\title{
Effect of bore fluid flow rate on formation and properties of hollow fibers
}

\author{
Asrar A. Alobaidy ${ }^{1} \cdot$ Bashir Y. Sherhan $^{2} \cdot$ Areej D. Barood $^{2} \cdot$ Qusay F. Alsalhy $^{2}$
}

Received: 25 April 2017/ Accepted: 20 June 2017/Published online: 28 June 2017

(c) The Author(s) 2017. This article is an open access publication

\begin{abstract}
In this work, for high performance and wide range of ultrafiltration applications, the effects of the most widely used values of internal coagulant flow rates (ICFR) (i.e., 2.6, 3.6, 4, 5, 7, 9, 11, and $13 \mathrm{ml} / \mathrm{min}$ ) on the different features of the polyvinylchloride hollow fiber have been investigated. Both the idealized straight and the cylindrical pore with small effect of tortuosity were approximately obtained through the effect of ICFR. Atomic force microscope (AFM), scanning electron microscope (SEM), and ultrafiltration measurements were utilized to characterize the hollow fibers. The SEM and AFM results indicated that the cross-sectional morphology of the fibers is changed significantly with various ICFR. The structure of the inner surface was also changed from an open cellular structure to a porous structure by means of high pore density and small pore diameter. In addition, the membrane thickness was reduced by $314 \%$ with an increase in the ICFR from 2.6 to $13 \mathrm{ml} / \mathrm{min}$. The pure water permeation flux was improved 17 times when ICFR was increased to $13 \mathrm{ml} / \mathrm{min}$, while the BSA rejection remained within the acceptable range (from 93.4 to 90.4 ) when the ICFR was increased from 2.6 to $9 \mathrm{ml} / \mathrm{min}$.
\end{abstract}

Bashir Y. Sherhan

bashiryoush1974123@yahoo.com;

80193@uotechnology.edu.iq

Qusay F. Alsalhy

qusay_alsalhy@yahoo.com; 80006@uotechnology.edu.iq

1 Chemical Engineering Department, College of Engineering, University of Baghdad, Baghdad, Iraq

2 Membrane Technology Research Unit, Chemical Engineering Department, University of Technology, Alsinaa Street 52, P.B.O 35010, Baghdad, Iraq
Keywords Hollow fiber · Ultrafiltration · PVC · Internal coagulant $\cdot$ Separation performance

\section{Introduction}

One of the main goals of membrane technology is to control both membrane pore size and distribution during the configuration, as they have a large impact on the separation performance of any membrane. Several factors affect membrane pore size and distribution such as composition of the polymer, composition and type of the additives, air-gap length, type and temperatures of inner and outer coagulants, flow rate of the polymer solution, flow rate of the internal coagulant, and the design of the spinneret. In fact, the flow rate of the internal clotting is the most significant factor influencing the membrane pore size and distribution (Jack et al. 2006). Therefore, one of the main goals of this effort is to investigate this hypothesis. The literature review indicated that the effect of the flow rate of the internal coagulant on the characteristics and performance of the fiber has not been extensively studied (Jack et al. 2006; Chung et al. 1977; Aptel et al. 1985; Mok et al. 1995; Miao et al. 1996; Qin and Chung 2004; Wan and Chung 2015; Cheng et al. 2017; Peng et al. 2012). For example, Chung et al. (1977) studied the fabrication of polyethersulfone (PES) membrane with ultrathin skin layer membranes of $50 \mathrm{~nm}$ skin layer thickness controlled by the lumen liquid flow rate and lumen liquid chemistry. Aptel et al. (1985) investigated the influence of the internal coagulant flow rate on characteristics of polysulfone (PSF) ultrafiltration. They reported that, as the nonsolvent flux in the lumen side of the nascent fiber increased from $4 \times 10^{-2}$ to $6 \times 10^{-2} \mathrm{~cm}^{3} / \mathrm{s}$, the hydraulic permeability also increased from $2 \times 10^{-8}$ to $6 \times 10^{-8} \mathrm{~cm} / \mathrm{s}-\mathrm{Pa}$. Whereas, rejection for polyvinylpyrrolidone [PVP,

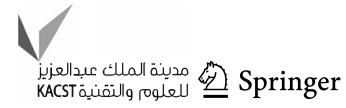


molecular weight $(\mathrm{MW})=10,000]$ decreased from 80 to $40 \%$. The influence of the internal coagulant flow rate, the temperature, and the composition of casting solution on the separation performance of PES membranes was investigated by Mok et al. (1995). These authors found that the outer to inner radius of the hollow fiber seems to decrease with the internal coagulant flow rate.

The influence of internal coagulant flow rates (7.5 and $5 \mathrm{ml} / \mathrm{min}$ ) on the properties of PES membranes made using dope spinning method was investigated by Miao et al. (1996). They reported that, at a constant air-gap length, by increasing the flow rate of the internal coagulant, both inner diameter (ID) and outer diameter (OD) can be enhanced with the reduction of the thickness of the wall for the formed membranes. The separation factor and permeability of UF membrane for polyethylene glycol (PEG) solutes reduced with the increase in the flow rate of the lumen-side coagulant due to the decrease in the skin layer thickness and the size of the skin layer pores, and narrow the pore size distribution on the skin layer. Moreover, Qin and Chung (2004) found that, as the flow rate of the internal coagulant diminished, the diameter of the inner PES membrane surface declined, while the diameter of the outer surface remained the same. Besides, as internal coagulant flow rate increases, the mass transport at the outer surface increases, while that at the inner surface is minimized, resulting in an increase in the macro-void length.

In fact, extensive work has been dedicated to the fabrication of PVC hollow fiber membranes for different separation applications. However, the effect of spinning parameters on either the fabrication of PVC fibers or the properties of the PVC fibers was not studied extensively. Membrane properties, especially permeability, can be affected by different resistances, which are a function of pore-size distribution, porosity, membrane barrier thickness, and the solvent properties, whilst both the idealized straight and the cylindrical pore with small effect of tortuosity are relevant to the influence of ICFR. Consequently, this study was focused on the impact of ICFR on the structural properties and membrane performance, as it exerts the greatest influence on the membrane thickness, size, and distribution of the pores. Inner and outer surface structures, as well as the fiber cross-section were characterized by SEM, and the ultrafiltration measurements were carried out using bovine serum albumin (BSA) with $\mathrm{MW}=67 \mathrm{~kg} / \mathrm{mol}$ as a solute.

\section{Experimental part}

\section{Materials}

The PVC resins and $N, N$-dimethylacetamide (DMAc) solvent were supplied by Sigma-Aldrich, while Chemical Co was used for membrane preparation. PVC with $\mathrm{Mw}$ of
$65 \mathrm{~kg} / \mathrm{mol}$ was obtained from Georgia Gulf Company (Georgia, USA). It was used as a membrane material in this study due to its excellent physical and chemical properties, stiffness, low cost, superior mechanical properties, and good solvent resistance.

\section{Polymer spinning solution}

PVC dope solution was prepared from $16 \mathrm{wt} \%$ PVC polymer and $84 \mathrm{wt} \%$ DMAc solvent. Dried PVC resin was gradually added into the covered container containing DMAc solvent and then mixed by a magnetic stirrer until the solution became clear and homogeneous.

\section{PVC/DMAc hollow fiber spinning procedure}

The PVC/DMAc homogenous solution was kept for at least $24 \mathrm{~h}$ to eliminate air bubbles. The PVC/DMAc solution was then transferred to a vertical column with $6 \mathrm{~cm}$ inner diameter. Throughout the entire spinning process, the temperature was maintained at $26{ }^{\circ} \mathrm{C}$. Hollow fibers were prepared using the dry/wet spinning method with various internal coagulant flow rates, as described elsewhere (Alsalhy et al. 2011, 2013; Alsalhy 2013). The dope polymer solution was forced via pressurized nitrogen to the spinneret of 0.5 and $0.9 \mathrm{~mm}$ inner and outer diameter, respectively. The PVC/DMAc ratio was $16 / 84 \mathrm{wt} \%$, and the fabrication conditions of the prepared PVC membranes were as follows: 1.75 bar extrusion pressure, $3 \mathrm{~cm}$ air-gap length, $19{ }^{\circ} \mathrm{C}$ external coagulation bath temperature with tap water, and bore fluid with various flow rates (i.e., 2.6, 3.6, 4, 5, 7, 9, 11, and $13 \mathrm{ml} / \mathrm{min}$ ).

The experimental apparatus and the process procedure were described elsewhere (Alsalhy et al. 2011, 2013, 2014; Alsalhy 2013). It is well known that water is always used as an internal and external coagulant in hollow fiber preparation and other membrane configurations due to the low cost of solvent and its good affinity and solubility with all of the polymer solvents. Therefore, in this work, water was used as the internal and external coagulant liquid. The prepared fibers were wetted and kept in a tap water bath at ambient temperature for $24 \mathrm{~h}$ to eliminate the residual DMAc solvent. PVC fibers were kept for $72 \mathrm{~h}$ in a container containing $40 \mathrm{wt} \%$ glycerol aqueous solution to avoid the fiber structure collapse. Prior to testing, the PVC fibers were dried in air at room temperature.

\section{SEM and AFM observations}

The internal and the external membrane structures were tested by means of scanning electron microscopy (SEM) at University of Technology/Nanotechnology and Advanced Material Research Center. The hollow fiber (HF) 
membranes were dried and then immersed in liquid nitrogen for $15 \mathrm{~s}$ and thereafter cut to reveal the cross-sectional structure.

AFM device (Angstrom Advanced Inc., Braintree, Boston, USA) model AA3000 was used to obtain 2D and 3D images of the membrane surface. The fiber was subjected to a wide surface analysis using an AFM in contact mode with a tip made from silicon. A statistical distribution of the pore size was estimated for the PVC surfaces of each membrane using IMAGER 4.31 software.

\section{Diameter, thickness, and porosity of PVC membranes}

The diameter and thickness of HF membranes were determined using optical microscope Model B600.POL-I S/N: 0016243, Italy.

Membrane porosity $(\varepsilon)$ is the ratio between the pore volume and the total membrane volume. Fiber porosity was measured using the procedure described elsewhere (Alsalhy et al. 2011). The fiber sample was dried in a vacuum oven for approximately $6 \mathrm{~h}$ at $80{ }^{\circ} \mathrm{C}$ to obtain constant hollow fiber weight. Then, the sample was weighed using a digital balance. According to the fiber weight and volume, fiber density $\left(\rho_{m}\right)$ was estimated, yielding the density of the polymer material $\left(\rho_{p}\right)$ of $1.4 \mathrm{~g} / \mathrm{cm}^{3}$ (Alsalhy et al. 2011). The total porosity was estimated using the following equation:

$\varepsilon(\%)=\left(1-\frac{\rho_{m}}{\rho_{p}}\right) \times 100$

\section{UF experiments}

Figure 1 shows the schematic drawing of performance rig. PVC membrane was examined in pack of five fibers, each of $20 \mathrm{~cm}$ length. The fibers were fixed at the ends of the module using epoxy resin. Pressure and feed solution flow rate of the performance test were $1 \mathrm{bar}$ and $1 \mathrm{~m} / \mathrm{s}$, respectively. Permeate was collected from the lumen side, while feed solution was moved to the shell side of the module. The BSA composition in the aqueous solution was $800 \mathrm{ppm}$. The BSA concentration was measured by a UVspectrophotometer (Shimadzu-UV160 A, Japan) at $\lambda=280 \mathrm{~nm}$. The BSA rejection factor $(F)$ was estimated according to the equation below (Alsalhy et al. 2011, 2013):

$F=\frac{C_{\text {feed }}-C_{\text {permeate }}}{C_{\text {feed }}}$

where $C_{\text {feed }}$ and $C_{\text {permeate }}$ are defined as the BSA concentration in the feed and permeate side of the hollow fiber, respectively.
Pure water permeation rate (PWP) can be estimated by applying the following equation:

$\mathrm{PWP}=\frac{V}{n A t \Delta P}$

where $V$ denotes the collected permeate volume, $n$ is the number of fibers in the bundle, $A$ is the membrane surface area, $t$ is the collected time, and $\Delta P$ is the transmembrane pressure.

\section{Results and discussion}

\section{SEM test}

Figures 2 and 3 provide the SEM images of the PVC hollow fibers prepared at various flow rates for the internal coagulant (distilled water). It can be seen that the inner structures and the cross-section are highly dependent on the internal coagulant flow rate on the lumen side of the fiber. The hollow fiber prepared from $16 \mathrm{wt} \%$ PVC dope under $2.6 \mathrm{ml} / \mathrm{min}$ internal coagulant flow rate comprises of two small layers forming a finger-like structure. These correspond to the inner and the outer surface of the cross-section depicted in Fig. 2a. Similarly, two large layers in the shape of finger and sphere-like structure can clearly be observed at the center of the cross-section of the membrane, as depicted in Fig. 2a. It can be seen in Fig. 2b that the two small layers at the inner and outer edges are reduced with increment of the internal coagulant flow rate to $3.6 \mathrm{ml} / \mathrm{min}$. On the other hand, the two fingers and the sphere-like structure layers at the center of the cross-section appear to be visibly changed because the layer towards the outer surface is transformed to a wide finger-like structure, while the layer towards the inner surface has become larger within the same spherical shape.

Under lumen liquid rate of $5 \mathrm{ml} / \mathrm{min}$, the layer in the center of the cross-section toward the external surface is seen to be merged with the layer located near the edge of the outer surface, and their final shape is transformed into a finger-like structure shown in Fig. 2c. However, the layer in the center of the cross-section toward the inner surface has been combined with the layer located near the inner edge of the fiber, whereby the final structure takes ellipsoidal shape, as shown in Fig. 2c. Further increase in the internal coagulant flow rate to $7 \mathrm{ml} / \mathrm{min}$ results in the two layers adopting the finger-like structure depicted in Fig. 2d. Moreover, due to the increase in the internal coagulant flow rate to $9 \mathrm{ml} / \mathrm{min}$, two layers with different structures are formed. The first small one is located near the outer surface and takes a finger-like form, while the second layer is found near the inner surface and forms an ellipsoidal-like structure, as exhibited in Fig. 2e. Further, increasing the 
Fig. 1 Schematic diagram of the UF experimental rig

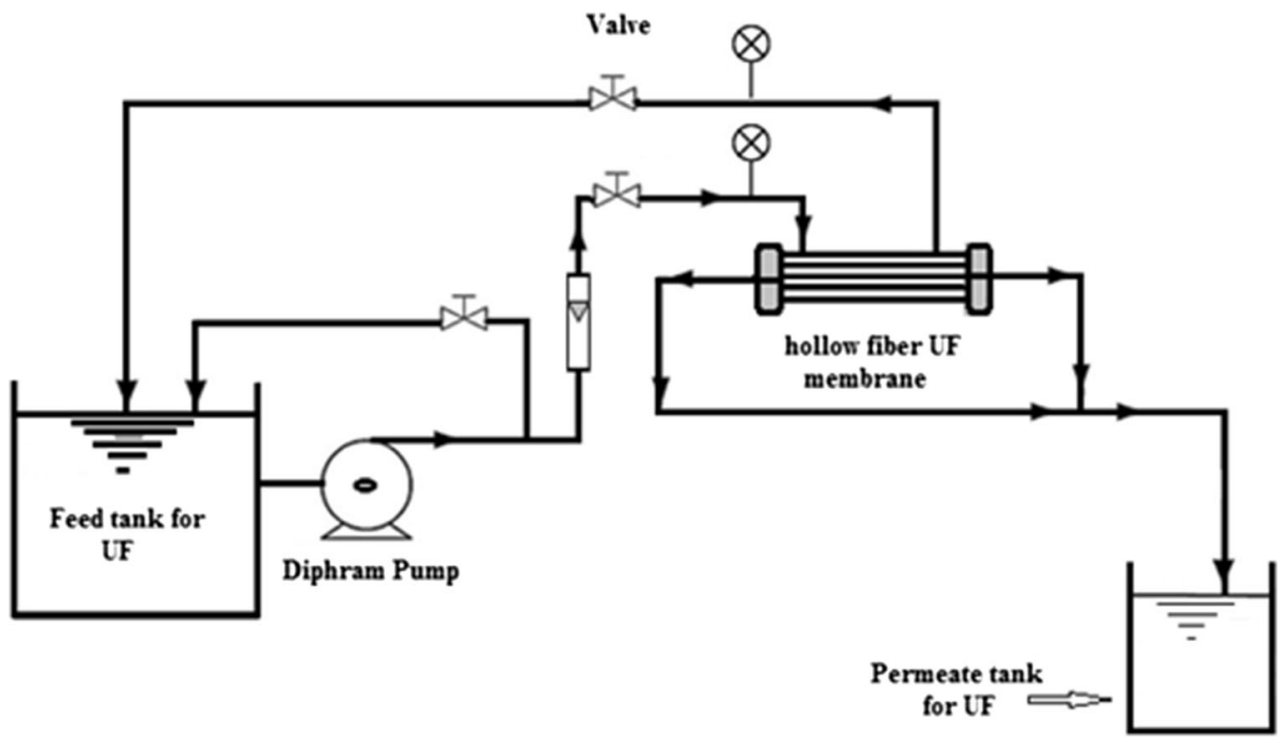

flow rate of the internal coagulant can be guided to create two layers of large finger-like structure with the same thickness such as that shown in Fig. 2f, even as the increase of the flow rate may be resulted to construct two layers of the finger-like structure, as shown in Fig. $2 \mathrm{~g}$. Figure 3 confirms the effect of internal coagulant flow rate on the inner surface structure of the hollow fiber membranes. It can be noticed that, as the internal coagulant flow rate increases, the obtained inner surface seems to be a skinless porous structure of the fiber membrane made under lumen liquid rate of internal coagulant of $3.6 \mathrm{ml} / \mathrm{min}$, as depicted in Fig. 3a. Increasing the flow rate of the internal coagulant to 5 and $7 \mathrm{ml} / \mathrm{min}$ has also led to the formation of the same structure, along with diminishing in the pore size at the surfaces, as shown in Fig. 3b, c.

Actually, this phenomenon is due to the speed of the demixing process of water in internal coagulant with the solvent of polymer solution, followed by domain growth that reaches the point of domain (droplet) coalescence. In this case, both phases keep their liquid character until coalescence occurs. This should prevent the formation of a skin layer at the fiber inner surface, resulting in the formation of a microporous surface (Zeman and Zydney 1996; Alsalhy et al. 2011). This phenomenon occurs when the demixing process of the solvent in the dope solution and water in the internal coagulant is delayed.

Additional increase in the internal coagulant flow rate to $9 \mathrm{ml} / \mathrm{min}$ can result in the emergence of a porous structure with small pore size, as shown in Fig. 3d. Increasing the internal coagulant flow rate to $13 \mathrm{ml} / \mathrm{min}$ might produce a surface with porous structure and high pore density, as observed in Fig. 3e, in comparison with that given in Fig. 3d. This observation can be attributed to the instantaneous liquid-liquid demixing process between DMAC in polymer solution and the water in internal coagulant due to the short contact time between high amount of water and DMAC in dope solution. The short contact time between bore fluid and dope solution can be explained by the high exchange rate between water in internal coagulant and DMAC solvent in polymer solution. This results in an instantaneous liquid-liquid demixing process, which in turn leads to the removal of high amount of solvent from the dope solution during the formation of the hollow fiber. Consistent with the last finding, the solidification occurred very rapidly within the small porous structure of high pore density. Porter (1990) reported that very high rates of precipitation (corresponding to short precipitation time) result in the formation of a finger-like micro-void structure. The use of a larger volume of bore fluid causes complete polymer precipitation as the non-solvent penetrates from the bore towards the outer surface of the fiber. Fast demixing process (higher precipitation rates) forms finer pores while delayed demixing process (slow precipitation rates) results in rough structures.

It can thus be concluded that internal coagulant flow rate is the main factor in controlling the pore size and density (Jack et al. 2006; Miao et al. 1996). As increasing the internal coagulant rate results in a 17 -fold increase in the permeation flux, this parameter has a significant impact on the membrane structure and/or membrane performance.

\section{Membrane thickness and porosity}

The most important factor affecting the barrier permeability is the membrane thickness owing to the direct relationship between the membrane thickness and both the shape and the size of pores. For this reason, our work focused on the effect of ICFR on the membrane properties. 
Fig. 2 Cross-section SEM images of the PVC hollow fiber membranes at various ICFR
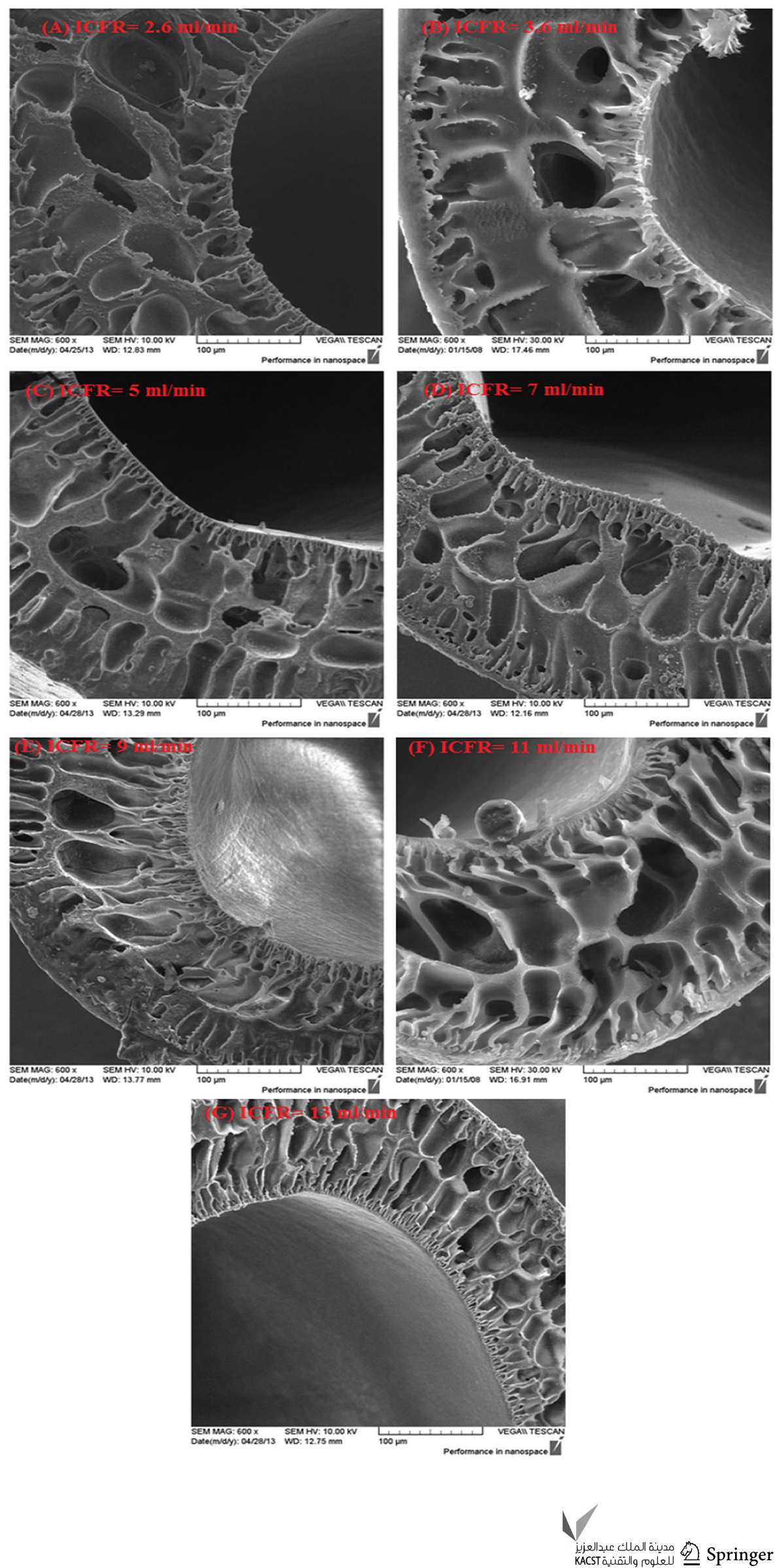

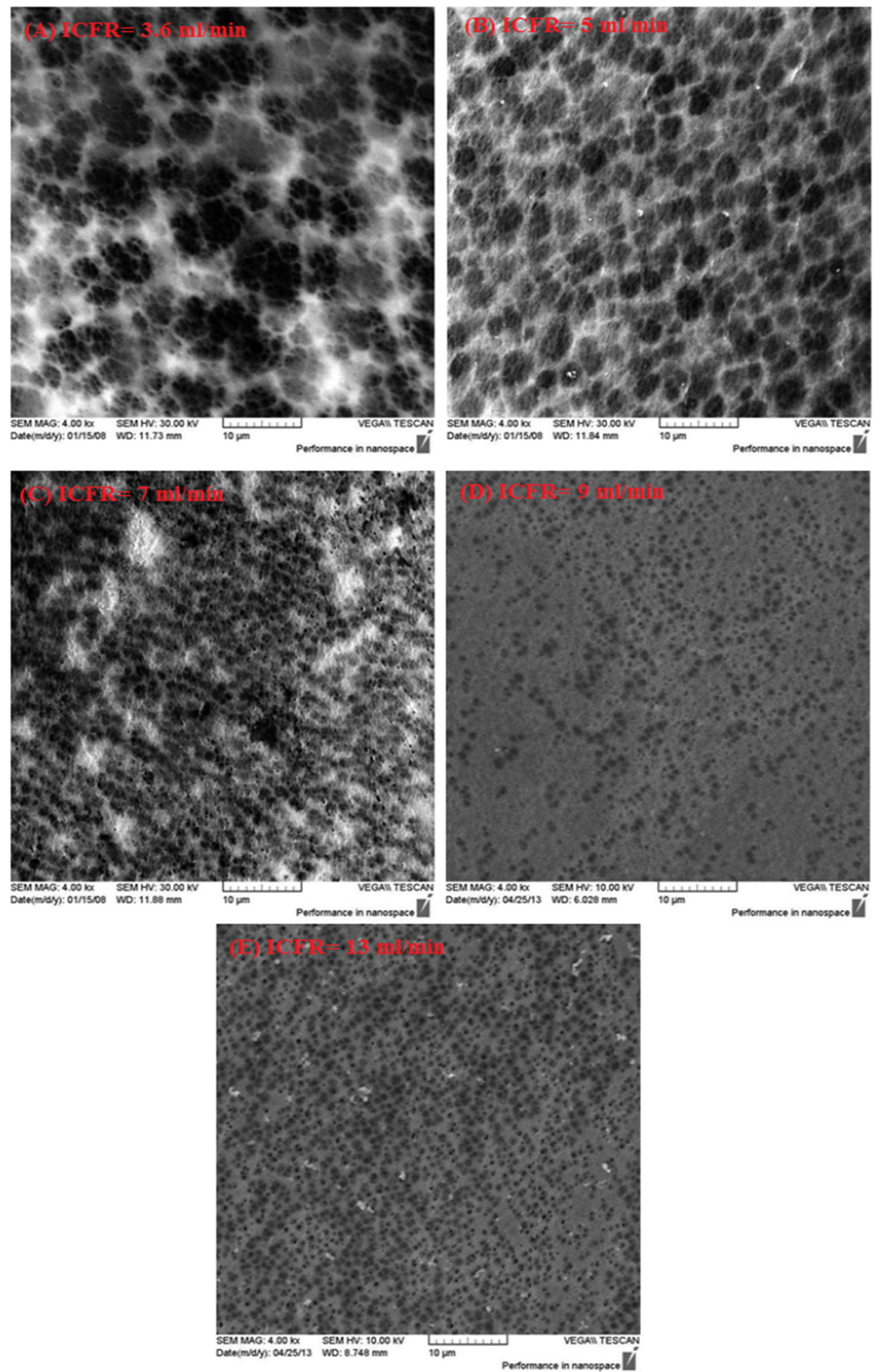

Fig. 3 SEM images of the inner surfaces of the PVC hollow fiber membranes at various ICFR

Figure 4 shows the effect of various ICFR on the membrane thickness. It can be noted that the membrane thickness decreases with increasing the ICFR from 2.6 to $13 \mathrm{ml} /$ min, and in this range of the ICFR, the membrane thickness reduces by $314 \%$. This observation is attributed to the effect of the internal pressure increase as a consequence of 
the increase in the amount of ICFR on the inner surface of the hollow fiber for the period of the spinning process, which ultimately leads to a reduction in the membrane thickness.

Table 1 summarizes the porosity of the hollow fibers with various ICFR. It can be noted that the effect of the ICFR on the porosity of the hollow fibers is insignificant.

\section{AFM analysis}

Three dimensions of AFM pictures of the inner surface for an area of $4000 \times 4000 \mathrm{~nm}$ for PVC fibers made using various bore fluid flow rates are presented in Fig. 5. A nodular structure can be observed in the inner surface of PVC membranes. The interconnected sinus trajectory between the conglomerated nodules on the inner skin of the membrane is also visible. After increasing the bore flow rate, the height of the nodules is reduced due to an increase in the density at the inner surface, as depicted in Fig. 5. This finding is supported by the earlier observation from the SEM images, which revealed a reduction in pore size on the surface and the elevation in pore density in conjunction with the increase of the bore flow rate at the lumen side of the hollow fiber. The effect of bore flow rate on the pore size and the pore density will be discussed at the end of this section. Both nucleation and growth (i.e., delayed liquid-liquid demixing process) of phase separation mechanism have taken place throughout the formation of the fiber skin as the lumen liquid rate is raised from 2.6 to $9 \mathrm{ml} / \mathrm{min}$. Conversely, the spinodal decomposition (i.e., fast liquid-liquid demixing process) of phase separation mechanism has occurred through the formation of the fiber skin when the lumen liquid rate was increased to 11 and $13 \mathrm{ml} / \mathrm{min}$. The variance in liquid-liquid demixing velocity at the inner surface of the PVC fibers is influenced by the

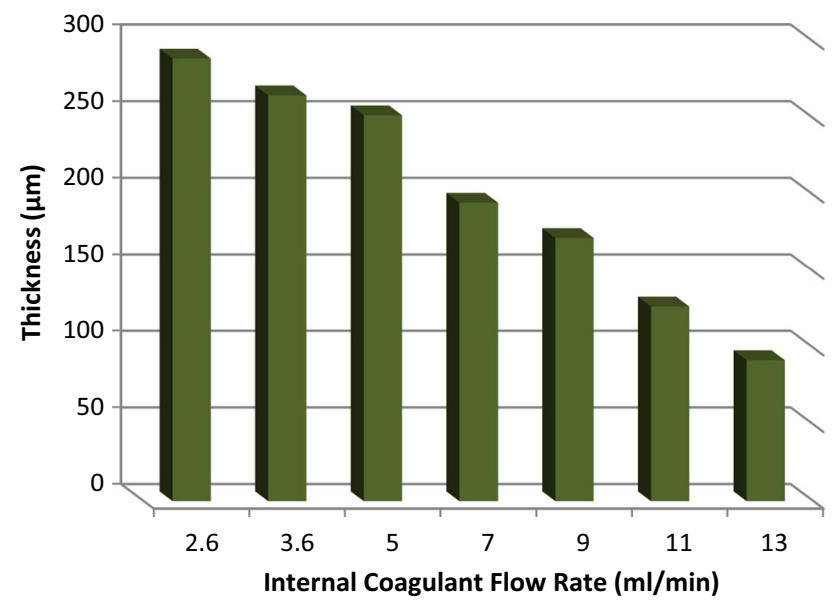

Fig. 4 Effect of ICFR on the hollow fiber thickness
Table 1 Effect of ICFR on porosity of the hollow fibers

\begin{tabular}{lll}
\hline Membrane no. & Internal coagulant flow rate $(\mathrm{ml} / \mathrm{min})$ & Porosity $(\%)$ \\
\hline 1 & 2.6 & 81.8 \\
2 & 3.6 & 81.9 \\
3 & 5 & 80.1 \\
4 & 7 & 80.8 \\
5 & 9 & 79.6 \\
6 & 11 & 81.8 \\
7 & 13 & 79.0 \\
\hline
\end{tabular}

lumen liquid rate, which can lead to the alteration of pore diameter and pore diameter distribution.

The inner surface of the hollow fiber prepared from low bore flow rate has large-sized pores, as shown in Fig. 5. Increasing the bore flow rate has resulted in a decrease in the pore size at the inner surface, as demonstrated in Fig. 5. The rate of the reciprocity of solvent and water can play a significant role in the formation of the skin of the PVC inner surface. Thus, a higher rate of reciprocity of solvent and water leads to the formation of skin with a porous structure because of the influence of speed of bore fluid at the lumen side of the fiber.

The average pore size, and the distribution of the pore size of inner surfaces and the pore size of outer surface of the PVC hollow fiber membranes, are estimated over an area of $4000 \times 4000 \mathrm{~nm}$, as shown in Figs. 6, 7, 8, and 9 . It could be seen that the average pore size of the fibers decreases gradually as the lumen liquid rate increases. For instance, the mean pore size of the hollow fibers is reduced from $146.27 \mathrm{~nm}$ at bore flow rate of $2.6 \mathrm{ml} / \mathrm{min}-104.7 \mathrm{~nm}$ at bore fluid flow rate of $13 \mathrm{ml} / \mathrm{min}$, as depicted in Fig. 6 . As discussed in the SEM analysis section, this occurrence is attributed to either fast mass transfer or fast reciprocity rate between the water in lumen liquid and the solvent in PVC solution, where the short contact time between them can result in high amount of solvent being taken out from the dope solution owing to the high amount of water flowing at the lumen side of the hollow fiber. For this reason, solidification occurs rapidly, and might result in the formation of small-sized pores. Figure 7 shows the effect of ICFR on the mean pore size of the outer fiber surface. It could be seen that the average pore size of the fibers is approximately the same despite increasing the lumen liquid rate, while increasing the lumen liquid rate from 9 to $13 \mathrm{ml} / \mathrm{min}$ results in increasing the mean pore size of the hollow fibers, as depicted in Fig. 7. Jack et al. (2006) found that, when the ICFR is high, the exchange rate of solventnon-solvent is expected to be high; thus, high pore size maybe observed.

The distribution of pore size of the PVC hollow fiber was studied according to the cumulative and the volume 
(A)

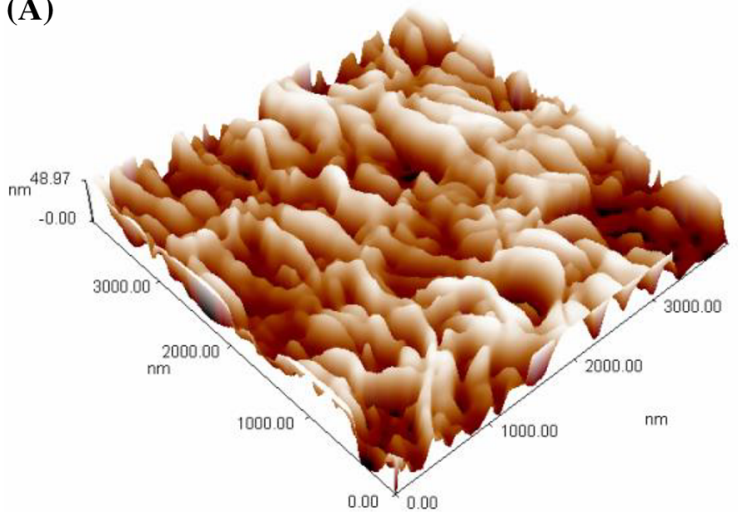

(C)

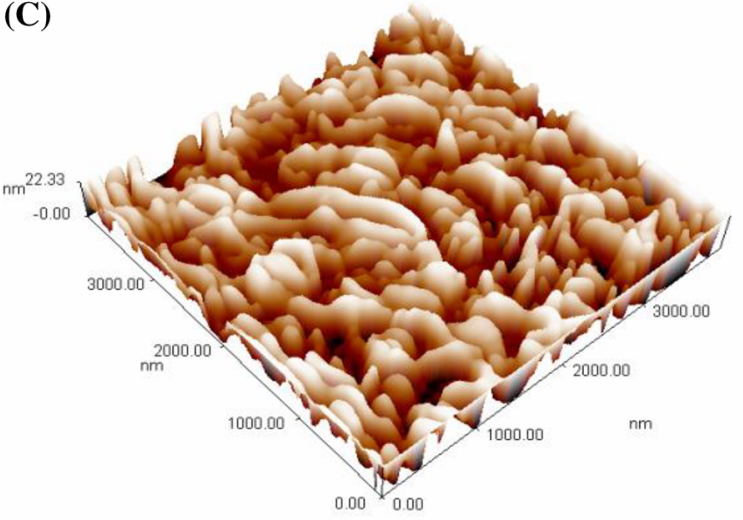

(E)
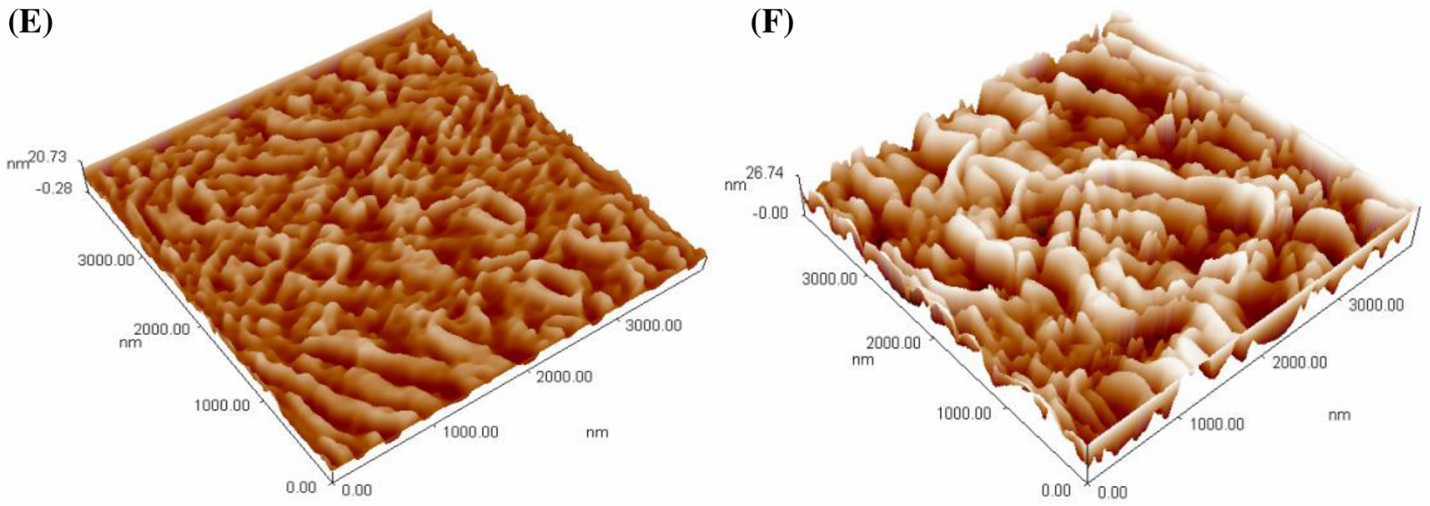

(B)

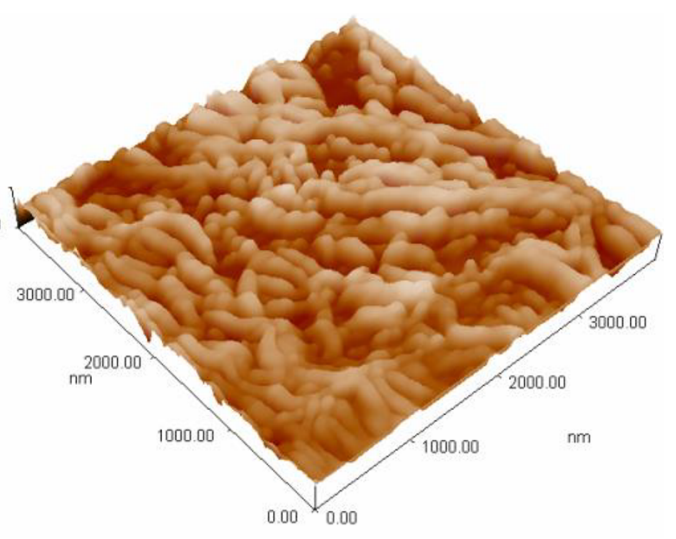

(D)

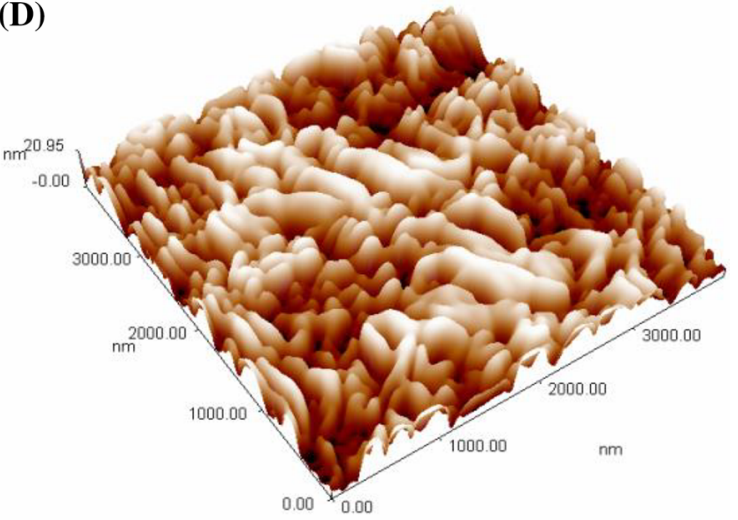

(F)

(G)

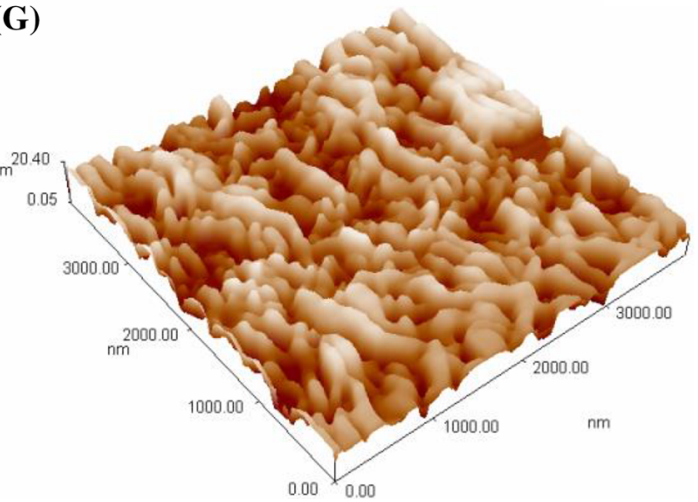


4Fig. 5 3D AFM images of the hollow fibers prepared from different effect of ICFR. a ICFR $2.6 \mathrm{ml} / \mathrm{min}$; b ICFR $3.6 \mathrm{ml} / \mathrm{min}$; c ICFR $5 \mathrm{ml} /$ $\mathrm{min}$; d ICFR $7 \mathrm{ml} / \mathrm{min}$; e ICFR $9 \mathrm{ml} / \mathrm{min}$; f ICFR $11 \mathrm{ml} / \mathrm{min}$; g ICFR $13 \mathrm{ml} / \mathrm{min}$

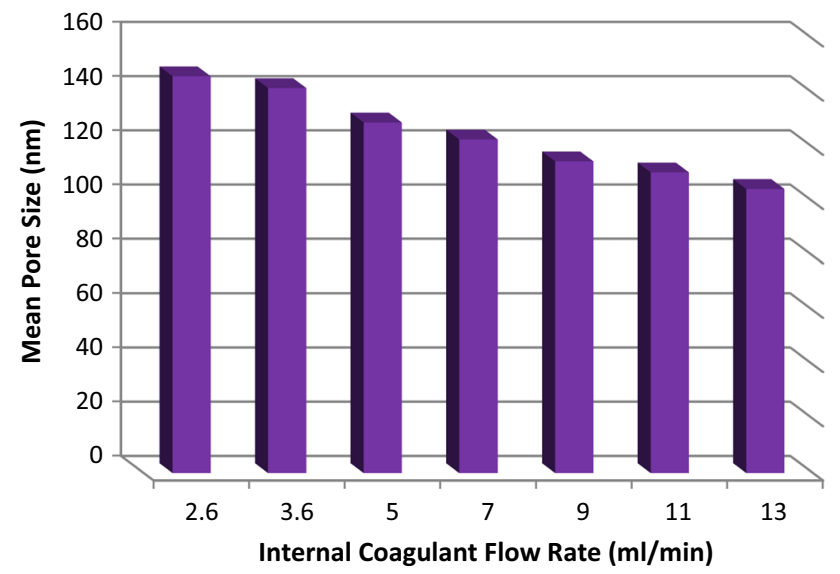

Fig. 6 Effect of ICFR on the mean pore size of the inner surface

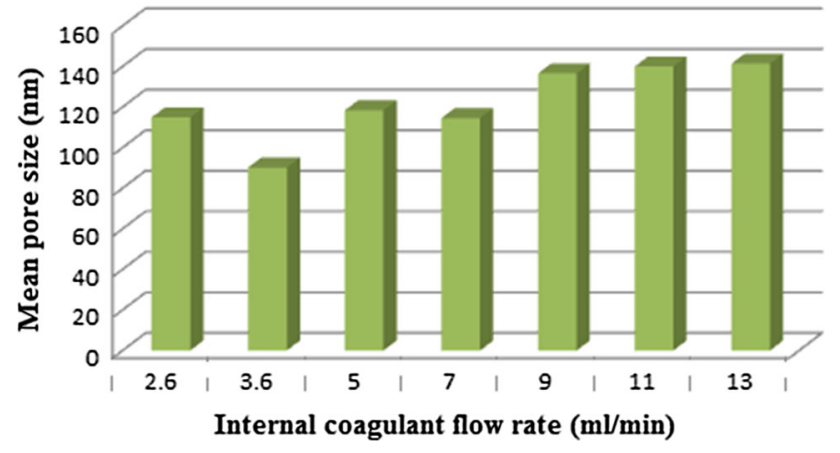

Fig. 7 Effect of ICFR on the mean pore size of the outer surface percentage of pore size, as illustrated in Figs. 8 and 9. As shown in Fig. 8, the cumulative percentage of the pore size at the inner surface at different bore flow rates is shifted to the left due to an increase in the lumen liquid rate. This means that the pore size at the inner surface follows a narrow distribution. Figure 8 also reveals that the volume percent of the inner diameter is shifted to the left as the bore flow rate increases. This observation corroborates the narrow range of the pore size on the inner surface. These results support the findings yielded by the SEM images of the inner surface.

\section{Influence of internal coagulant rate on hollow fiber performance}

The hollow fibers synthesized under various internal coagulant flow rates can be described by the pure water permeation and protein (i.e., Bovine serum albumin, BSA) rejection. Figures 10 and 11 depict the measured values of PWP and BSA retention of various hollow fibers synthesized under various internal coagulant flow rates. It can be seen from Fig. 10 that the PWP of the membranes is improved from 6.97 to $119.3\left(1 / \mathrm{m}^{2} \mathrm{~h}\right.$ bar $)$ due to the increase in the internal coagulant flow rate from 2.6 to 13 $(\mathrm{ml} / \mathrm{min})$. In other words, the PWP is enhanced by approximately 17 times. This observable fact is attributed to the change in the morphology of the synthesized fiber as discussed in the preceding section and explained in Figs. 2 and 3. The most significant factor can be noted in Fig. 3, depicting the reduction of average pore diameter of membrane with high pore density, along with the increase of internal coagulant flow rates. The results of AFM analysis shown in Fig. 5 confirm this phenomenon.
Fig. 8 Cumulative distribution of the pore size of the inner surface

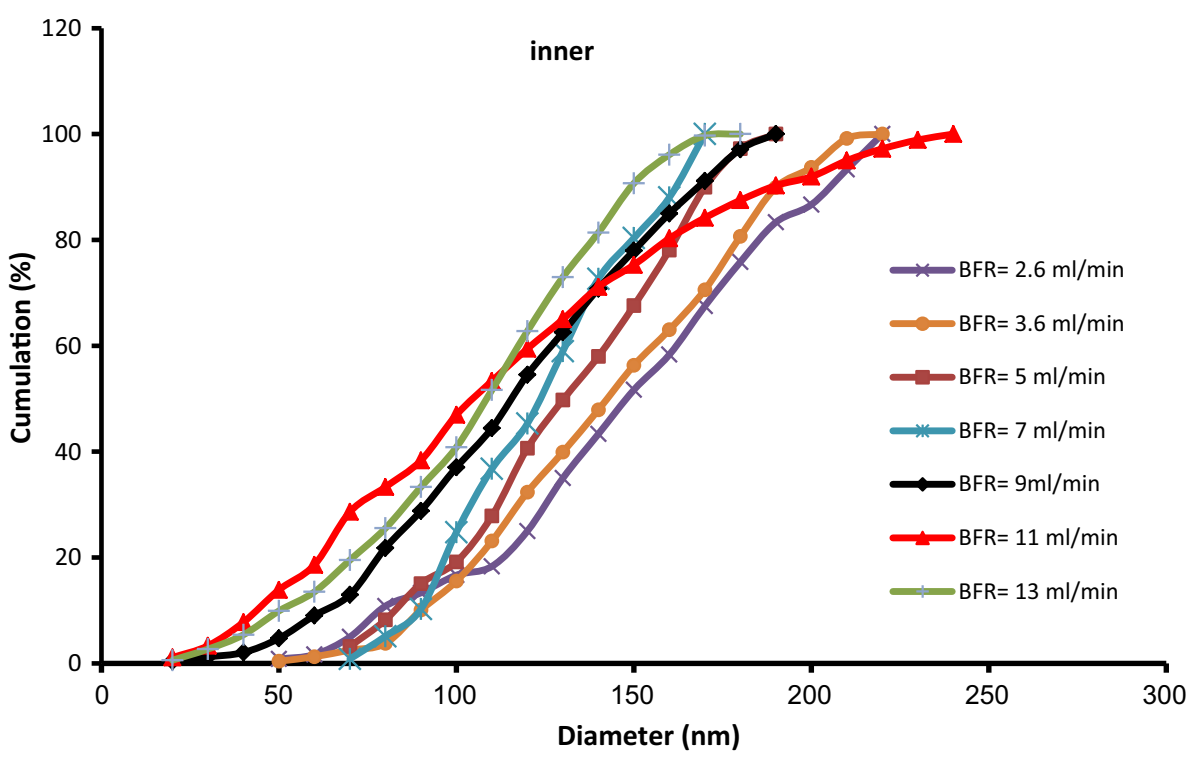


(A)

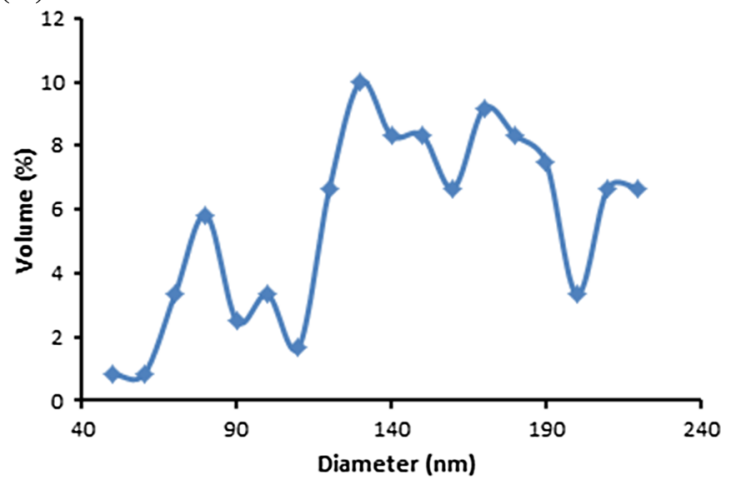

(C)

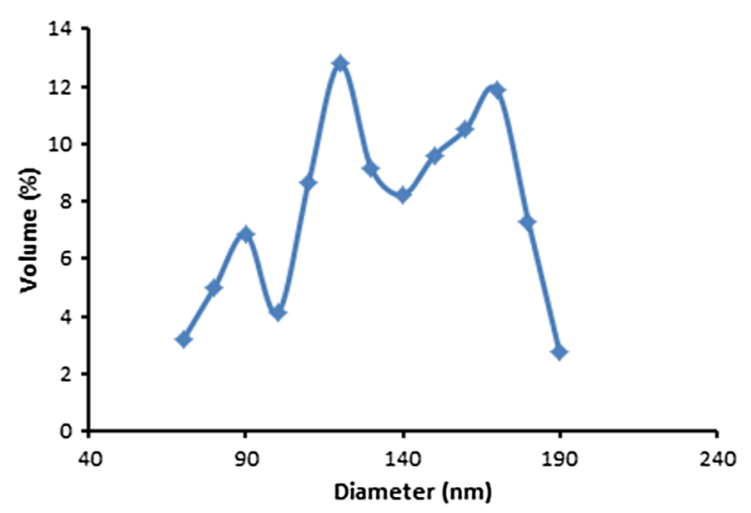

(E)

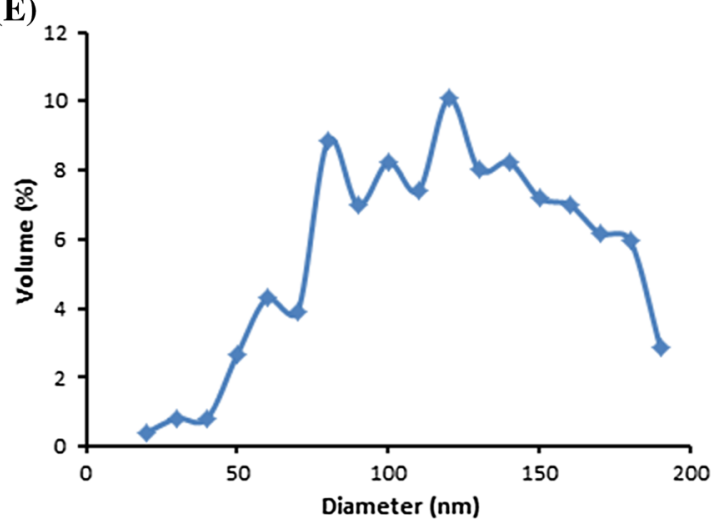

(B)

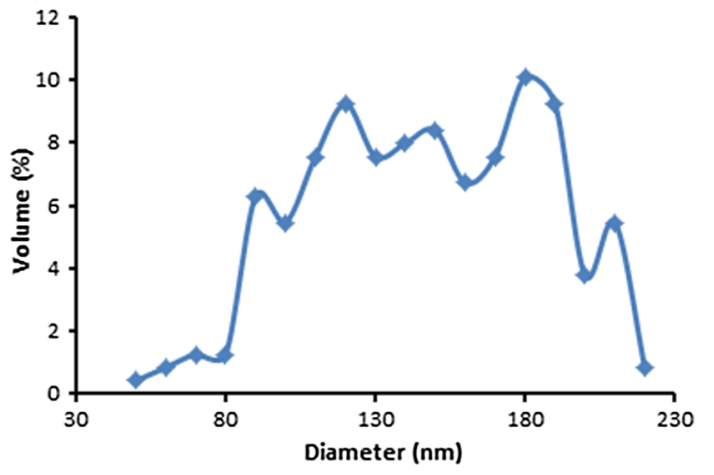

(D)

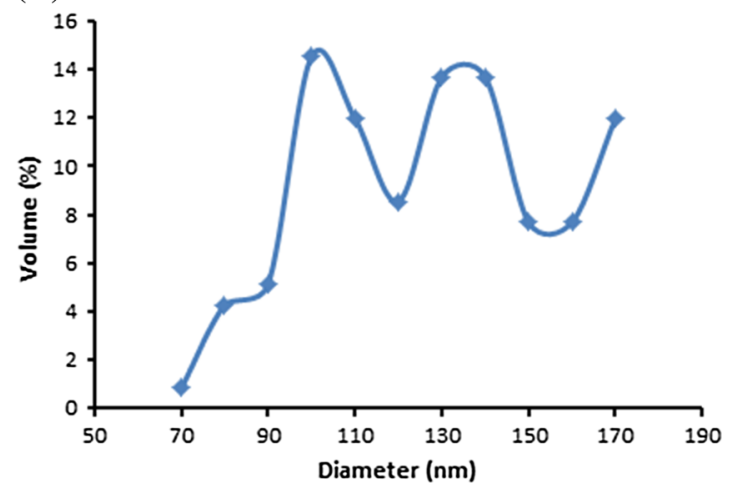

(F)

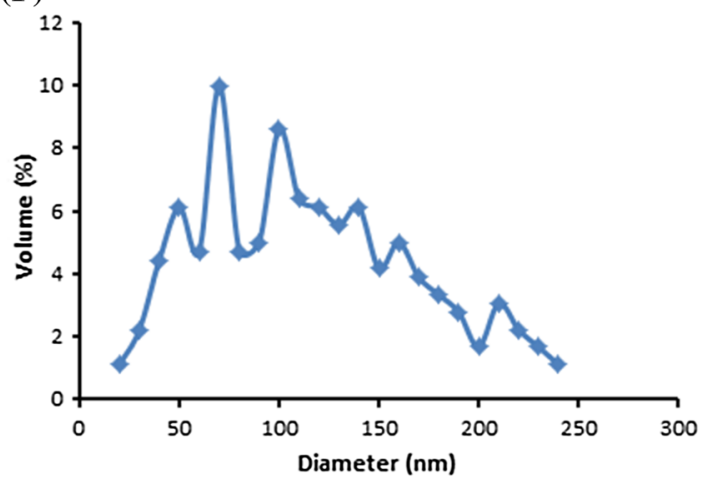

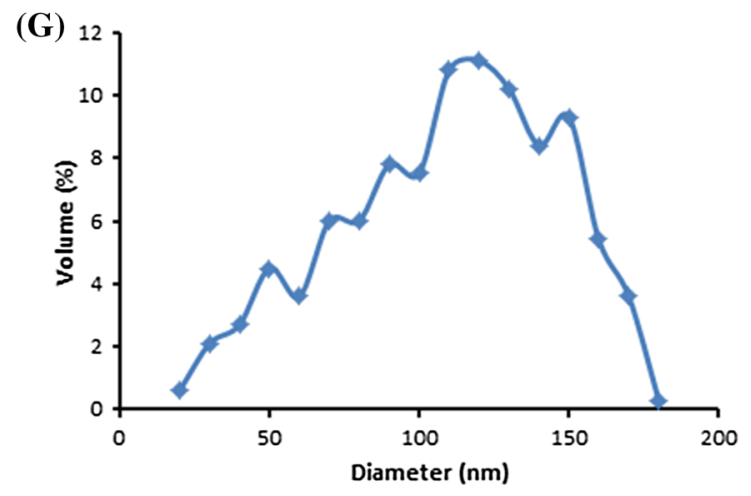

Fig. 9 Pore size distribution of the inner surface 


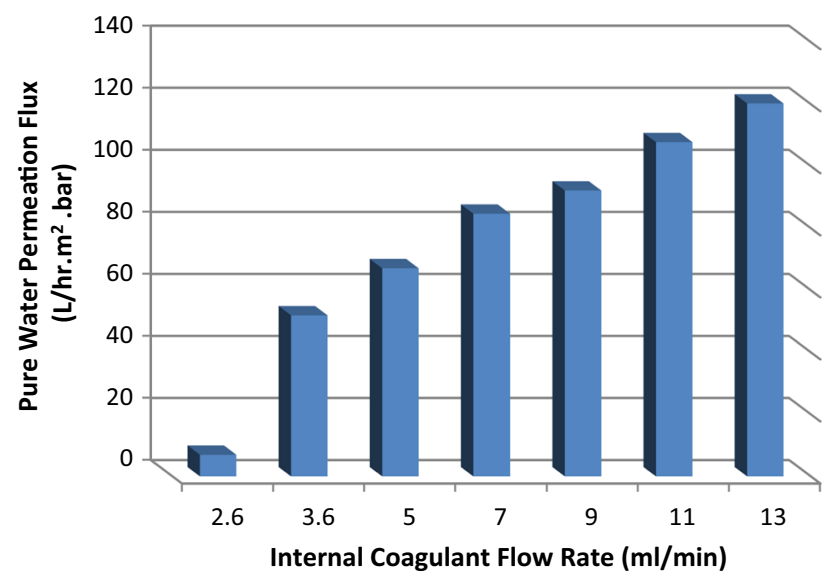

Fig. 10 Effect of various ICFR on pure water permeation flux of the fibers

Besides, $314 \%$ reduction in membrane thickness is also responsible for the increase in PWP. Kim et al. (2008) found that the PWP might be dependent on the number of pores (i.e., pore density) that appear on the membrane surface. Regarding the BSA separation performance, Fig. 11 shows the effect of internal coagulant flow rate on the BSA repudiation. It can be observed that the BSA rejection decreases from 93.4 to $90.4 \%$ with the increase of internal coagulant flow rate from 2.6 to $9 \mathrm{ml} / \mathrm{min}$. Further increasing the coagulant flow rate to 11 and $13 \mathrm{ml} / \mathrm{min}$ has led to a decrease in the BSA rejection to 78.3 and $76.1 \%$, respectively, as shown in Fig. 11. It is worth noting the 17 -fold increase in the pure water permeation, which was achieved without a considerable refusal in the solute rejection with increasing internal coagulant flow rates. According to the pertinent literature, structural morphology has a strong effect on the separation performance of the membrane because it is affected by the speed of solvent/ non-solvent exchange rate for the period of hollow-fiber membrane formation in the spinning process. In addition, the pore size of the outer surface of the fibers has a strong effect on the solute rejection, as shown in Fig. 7. Xu and Alsalhy (2004) and Alsalhy (2012) reported that the lower solute rejection was affirmed for membranes having larger pore diameter. The membrane pore density is thus another significant factor in the solute rejection of the membranes.

\section{Conclusions}

The internal coagulant flow rate (ICFR) in lumen side of the hollow fiber through the spinning operation is one of the most influential factors determining fiber properties. Therefore, the influences of various ICFR (e.g., 2.6, 3.6, 5, $7,9,11$, and $13 \mathrm{ml} / \mathrm{min}$ ) on the structural morphology and ultrafiltration properties have been deduced. From the experimental results, it can be concluded that excessively high ICFR within a constantly flowing PVC dope solution leads to an inner membrane surface with a high pore density, small pore diameter, and small skin layer. Whereas, an overly low ICFR flow can result in the formation of an inner membrane surface with open cellular structure. This is due to the change of the demixing process at different ICFR, as well as the delay in the instantaneous liquid-liquid demixing process of both the solvent in the dope solution and the water in the internal coagulant. Our findings further indicate that the membrane thickness was reduced by $314 \%$ when the ICFR was increased from 2.6 to $13 \mathrm{ml} / \mathrm{min}$. In addition, the pure water permeation flux was improved by 17 times with an increase in the ICFR up to $13 \mathrm{ml} / \mathrm{min}$, while the $\mathrm{BSA}$ rejection was changed from
Fig. 11 Effect of various ICFR on protein rejection of the fibers

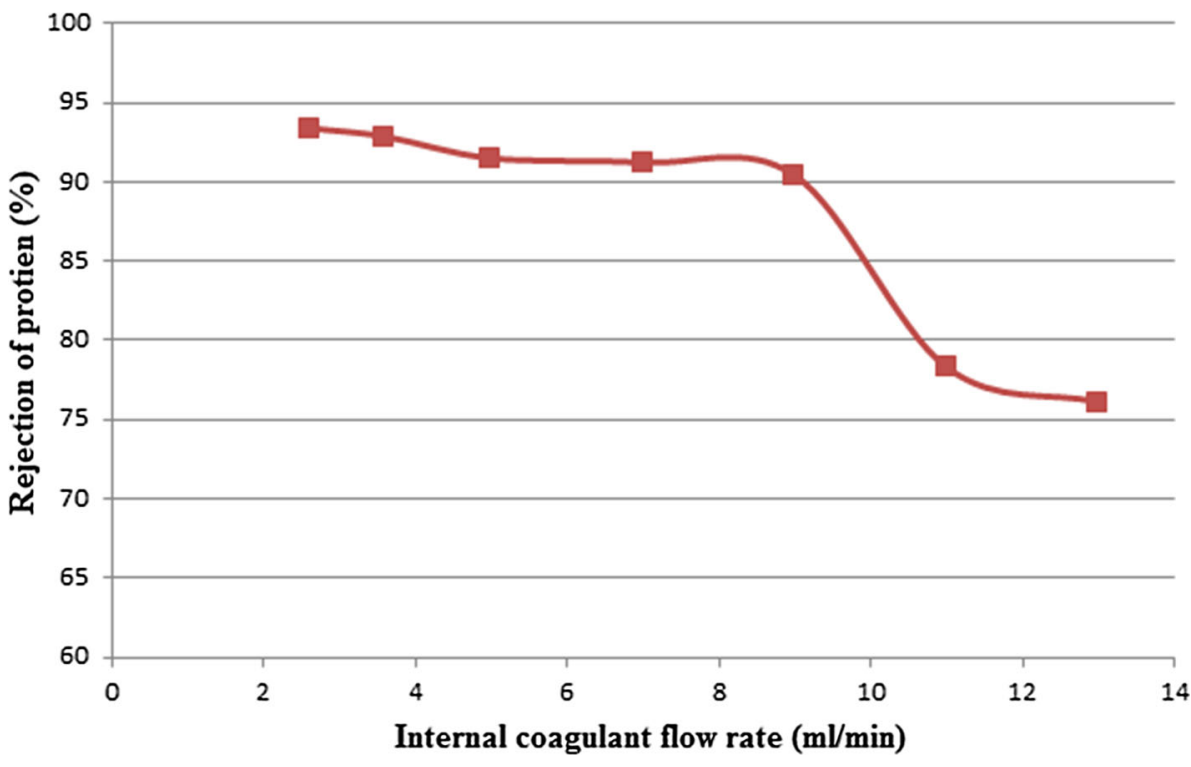

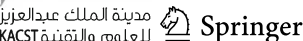


93.4 to 90.4 as the ICFR increased from 2.6 and $9 \mathrm{ml} / \mathrm{min}$ as a result of high pore density, reduced membrane thickness, and small pore size.

Open Access This article is distributed under the terms of the Creative Commons Attribution 4.0 International License (http:// creativecommons.org/licenses/by/4.0/), which permits unrestricted use, distribution, and reproduction in any medium, provided you give appropriate credit to the original author(s) and the source, provide a link to the Creative Commons license, and indicate if changes were made.

\section{References}

Alsalhy QF (2012) Hollow fiber ultrafiltration membranes prepared from blends of poly (vinyl chloride) and polystyrene. Desalination 294:44-52

Alsalhy QF (2013) Influence of spinning conditions on the morphology, pore size, pore size distribution, mechanical properties and performance of PVC hollow fiber membranes. Sep Sci Technol 48:234-245

Alsalhy QF, Algebory S, Alwan GM, Figoli A, Simone S, Drioli E (2011a) Hollow fiber ultrafiltration membranes from poly(vinyl chloride): preparation, morphologies and properties. Sep Sci Technol 46(14):1-12

Alsalhy QF, Algebory S, Alwan GM, Simone S, Figoli A, Drioli E (2011b) Hollow fiber ultrafiltration membranes from poly(vinyl chloride): preparation, morphologies, and properties. Sep Sci Technol 46:2199-2210

Alsalhy QF, Rashid KT, Ibrahim SS, Ghanim AH, Van der Bruggen B, Luis P, Zablouk M (2013) Poly(vinylidene fluoride-cohexafluropropylene) (PVDF-co-HFP) hollow fiber membranes prepared from PVDF-co-HFP/PEG-600Mw/DMAC solution for membrane distillation. J Appl Polym Sci 129:3304-3313

Alsalhy QF, Salih HA, Simone S, Figoli A, Zablouk M, Drioli E (2014) Poly (ether sulfone) (PES) hollow-fiber membranes prepared from various spinning parameters. Desalination 345:21-35

Aptel P, Abidine N, Ivaldi F, Lafaille JP (1985) Polysulfone hollow fibers-effect of spinning conditions on ultrafiltration properties. J Membr Sci 22:199-215
Cheng ZL, Li X, Feng Y, Wan CF, Chung TS (2017) Tuning water content in polymer dopes to boost the performance of outer selective thin-film composite (TFC) hollow fiber membranes for osmotic power generation. J Membr Sci 524:97-107

Chung TS, Teoh SK, Hu X (1977) Formation of ultrathin highpermeance polyethersulfone hollow fiber membrane. J Membr Sci 133:161-175

Jack U, Hendry BA, Jacobs EP (2006) Fabrication of wet phase inversion capillary membrane, dimension and diffusion effects, Ph.D. thesis, Cape Peninsula University of Technology

Kim N, Kim CS, Leeb YT (2008) Preparation and characterization of polyethersulfone membranes with p-toluenesulfonic acid and polyvinylpyrrolidone additives. Desalination 233:226-236

Miao X, Sourirajan S, Zhang H, Lau WWY (1996) Production of polyethersulfone hollow fiber ultrafiltration membranes. Part I. Effects of water (internal coagulant) flow rate and length of air gap. Sep Sci Technol 31:141

Mok S, Worsfold DJ, Fouda AE, Matsuura T, Wang S, Chan K (1995) Study on the effect of spinning conditions and surface treatment on the geometry and performance of polymeric hollow fiber membranes. J Membr Sci 100:183-192

Peng N, Widjojo N, Sukitpaneenit P, Teoh MM, Lipscomb GG, Chung TS, Lai JY (2012) Molecular design of polymeric hollow fibers as sustainable technologies: past, present, and future. Prog Polym Sci 37:1401-1424

Porter M (1990) Synthetic membranes and their preparation. In: Porter MC (ed) Handbook of industrial membrane technology, 1 st edn. Elsevier, Amsterdam

Qin JJ, Chung TS (2004) Effects of orientation relaxation and bore fluid chemistry on morphology and performance of polyethersulfone hollow fibers for gas separation. J Membr Sci 229:1-9

Wan CF, Chung TS (2015) Osmotic power generation by pressure retarded osmosis using seawater brine as the draw solution and wastewater brine as the feed. J Membr Sci 479:148-158

$\mathrm{Xu}$ ZL, Alsalhy QF (2004) Polyethersulfone (PES) hollow fiber ultrafiltration membrane prepared by $\mathrm{PES} /$ non-solvent/NMP solution. J Membr Sci 233:101-111

Zeman LJ, Zydney AL (1996) Microfiltration and ultrafiltration: principles and applications. Marcel Dekker, Inc., New York, p 91 (chapter 2) 